\title{
Enfermedad de Fahr
}

\section{Fahr's disease}

Entre las múltiples causas de calcificaciones en el SNC, la enfermedad de Fahr o calcificación idiopática de los ganglios de la base 0 calcinosis estriadopalidodentado bilateral es una rara enfermedad neurodegenerativa caracterizada por la acumulación de depósitos de calcio, en los ganglios de la base y otras regiones cerebrales ${ }^{1}$, visualizados mediante pruebas de imagen (TC o RM) ${ }^{2}$.

Presentamos el caso de una mujer de 64 años diagnosticada de retraso mental leve-moderado, trastorno de conducta, síndrome eutiroideo enfermo, anemia ferropénica y deficit de ácido fólico en tratamiento habitual con: risperidona, sulfato ferroso, ácido fólico y levotiroxina; que ingresa por bacteriemia por E. coli de origen urinario. No refiere antecedentes patológicos de interés relacionados con su enfermedad actual.

En la exploración neurológica no presenta alteraciones groseras pero dado el evidente retraso mental de la paciente no se pueden descartar alteraciones menores.

En los análisis realizados destaca calcemia 8,4 mg/dL (N: 8,5-10,5), 25OH vitamina D 9,9 ng/dL (N: 20-100), y PTH 66,2 pg/dL (N:14-72) que descartó la presencia de enfermedad endocrino- metabólica que explicase el cuadro, así como otros procesos infecciosos o sistémicos asociados a estos hallazgos.

En la TC cerebral: se observan calcificaciones bilaterales y simétricas localizadas en sustancia blanca subcortical, supratentorial, ganglios de la base (Fig 1) y hemisferios cerebelosos (Fig 2) que no serían compatibles con otras enfermedades como abscesos, neurocisticercosis, gliomas, craneofaringioma o neurofibromatosis.

La enfermedad de Fahr puede cursar con formas asintomáticas o presentaciones diversas que van desde: parkinsionismo, corea, deterioro cognitivo 0 ataxia ${ }^{1}$; siendo los trastornos del movimiento lo más frecuente. El tamaño de la calcificación se relaciona con la gravedad de la sintomatología pero la localización y severidad de la misma no reflejan toda la diversidad clínica. Su fenotipo es variable reconociéndose formas esporádicas y familiares (el patrón de herencia es autosómico dominante en la mayoría de los casos) ${ }^{3}$. Recientemente se han descubierto genes implicados en dicha entidad como son SLC20A2 y PDGFRB con pocas diferencias clínicas entre ellos; si bien es cierto que los portadores de la mutación PDGFRB no han presentado calcificaciones en la cortical ni en vérmix.

Es un hallazgo incidental objetivable hasta en el 12,5\% de los TC cerebrales realizados por motivos no relacionados, según las últimas series ${ }^{5}$.

No existen tratamientos específicos en la actualidad, ni aquellos que limiten la progresión de la enfermedad.

La paciente estaba diagnosticada de retraso mental pero al parecer llegó a ser capaz de completar estudios primarios. En la actualidad no leía ni escribía, por lo que no puede descartarse que su deterioro cognitivo actual sea secundario a la enfermedad de Fahr.

\section{Bibliografía}

1. Bilateral striopallidodentate calcinosis: clinical characteristics of patients seen in a registry. Manyam BV, Walters AS, Narla KR. Mov Disord. 2001;16(2):258

2. CT findings in Fahr's disease.Alam ST, Aswani Y, Anandpara KM, Hira P. BMJ Case Rep. 2015 Mar 20;2015

3. Phenotypic spectrum of probable and genetically-confirmed idiopathic basal ganglia calcification. Nicolas G, Pottier C, Charbonnier C, Guyant-Maréchal L, Le Ber I, Pariente J, et al. Brain. 2013 Nov; 136(Pt 11):3395-407

4. The significance of the incidental finding of basal ganglia calcification on computed tomography. Harrington MG, Macpherson P, Mclntosh WB, Allam BF, Bone I. J Neurol Neurosurg Psychiatry. 1981;44(12):1168.

5. Bilateral strio-pallido-dentate calcinosis (Fahr's disease): report of seven cases and revision of literature. Savino E, Soavi C, Capatti E, Borrelli M, Vigna G, Passaro A et al. BMC Neurol. 2016 Sep 8;16:165
Figura 1. Imagen TC cerebral: calcificaciones de los ganglios de la base

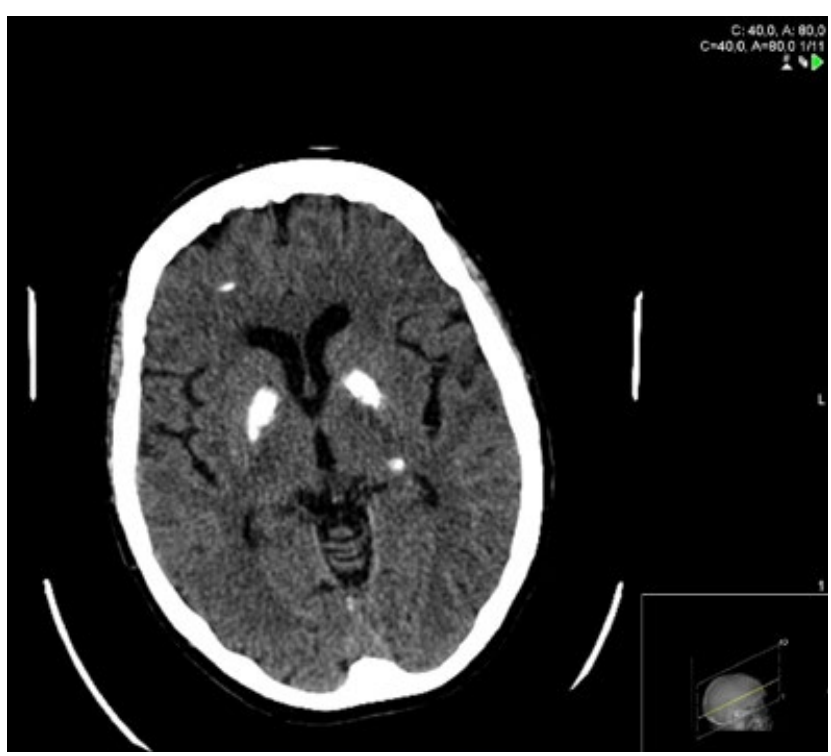

Figura 2. Imagen TC cerebral: calcificaciones en ambos hemisferios cerebelosos

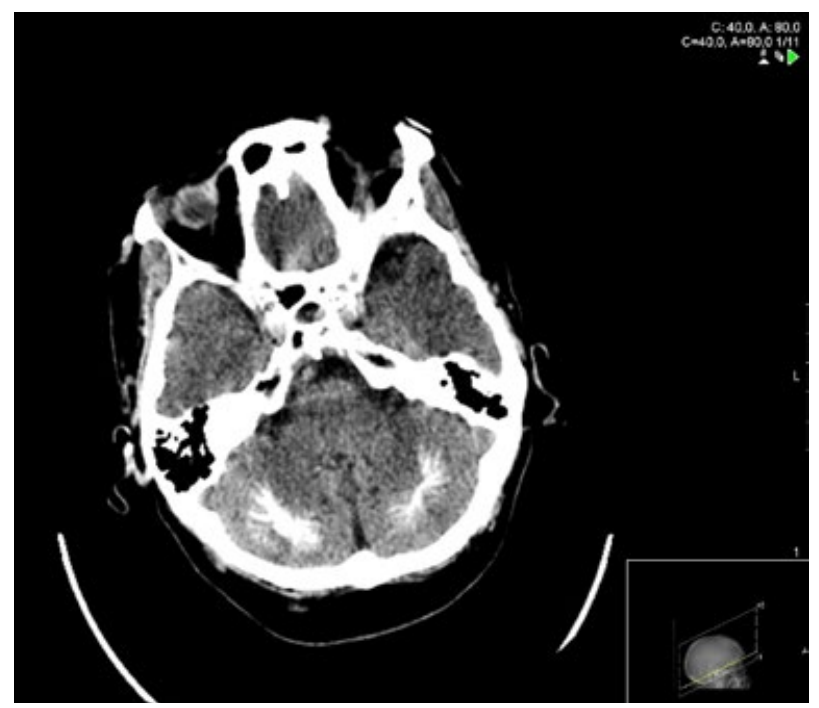

\section{Diagnóstico: Enfermedad de Fahr}

Beatriz García Trincado, Francisco Terrón Pérez

Servicio de Medicina Interna. Hospital Universitario Lucus Augusti (Lugo)

Correspondencia: beatriz.garcia.trincado@gmail.com

Como citar este artículo: García Trincado B, Terrón Pérez $F$

Enfermedad de Fahr. Galicia Clin 2017; 78 (1): XX-XX

Recibido: 21/07/2016; Aceptado: 30/07/2016 